about animal work. The surveillance by Her Majesty's inspectors and, just as important, the personal qualities of research workers and animal house technicians ensure that no unnecessary suffering is inflicted on animals and that they are handled with care and kindness.

Many antivivisectionists seem sadly ignorant of the suffering and misery caused by disease to their fellow citizens and of the benefits which have been derived and will continue to be derived from animal work. Some of their claims are part of the current vogue of antiestablishment campaigning supported, too often sensationally, by journalists: conventional medicine is castigated as inferior to acupuncture, nature cures, homoeopathy, and anthroposophic medicine which have the added advantage that they do not require support from animal experiments. Claims that cancer research is unnecessary and that scientists want the public to contribute to cancer research funds merely so that they can go on enjoying the pleasures of vivisection would be ludicrous except that they are taken seriously.

The threat of the antivivisectionists to medical research is not insubstantial: many wish to modify the 1876 Act so that animal work is abolished, and some of the more extreme are prepared to break into buildings, release animals, smash equipment, and send letter bombs to research workers or prominent medical men.

Experience in Birmingham in the past few weeks has shown, however, that the public welcomes authoritative statements that answer the allegations made by the antivivisectionists, does appreciate the benefits derived from animal work, and discounts the hysterical claims that such work is senseless, unnecessary, barbaric, inhuman, and immoral. The profession must argue against the exaggerated claims of the antivivisectionists: an important freedom to pursue justifiable ends to advance scientific knowledge is otherwise threatened.

O L WADE

Dean of the Faculty of Medicine and Dentistry,

University of Birmingham,

Birmingham B15 2TT

${ }^{1} \mathrm{HM}$ Government. Cruelty to animals Act 39 and 40. Ch 77. London: HMSO, 1876.

2 Anonymous. Vivisection at Alfort. Lancet 1860;ii:395-6.

3 Anonymous. Justifiable vivisection. Br Med $\mathcal{F} 1864 ; \mathrm{i}: 71$.

${ }^{4}$ Adams C. The antivivisection movement and Miss Cobbe. Verulam Review 1892;3:201. (Quoted by French. ${ }^{6}$ )

${ }^{5}$ Home Office. Statistics of experiments on living animals, Great Britain. London: HMSO, 1980. (Cmnd 8306.)

${ }^{6}$ French RD. Antivivisection and medical science in Victorian society. Princeton, New Jersey: Princeton University Press, 1975:62.

\section{Psychosocial factors in the cause and prevention of relapse in schizophrenia}

Schizophrenia is a recurring or chronic condition, and its course is no longer thought to be one of progressive deterioration. ${ }^{1}$ Most patients either have frequent episodes of florid psychosis with hallucinations and delusions or have these symptoms as a permanent feature, but those more severely affected are also vulnerable to the social poverty and understimulation that may occur in large institutions such as mental hospitals or living alone in the community. A consistent line of research by social psychiatrists and sociologists over 25 years has improved our understanding of the role of $\underline{w}$ psychosocial factors in determining the course of schizophrenia 3 and its treatment.

That schizophrenics may be particularly susceptible to "total institutions"2 was shown by Wing and Brown in a controlled study. ${ }^{3}$ They found that chronic symptoms, such $\frac{}{J}$ as social withdrawal and poverty of speech, varied from one $\mathbb{\Phi}$ hospital to another according to the severity of ward restric- 1 tiveness, absence of personal belongings, and the length of $\frac{\text { ? }}{\mathrm{c}}$ time that patients were left to do nothing. Acute symptoms of hallucinations and delusions were provoked when patients with chronic schizophrenia were stressed by attempts at too $\frac{C}{0}$ rapid rehabilitation. ${ }^{4}$ These early findings suggested that $\frac{}{\bar{m}}$ schizophrenics had heightened sensitivity to social deprivation, $\stackrel{\nabla}{\varnothing}$ leading to withdrawal and regression, and to social stress, which provokes an acute exacerbation of symptoms. ${ }^{3}$

The main thrust of this research came from the MRC? Psychiatry Unit in London, though it has since been extended $\vec{\omega}$ and confirmed elsewhere. In subsequent studies Brown and $\frac{\partial}{\partial}$ colleagues noticed that relapse was more common among schizophrenics who were discharged to live with a spouse or parent than among those living alone or in a hostel, ${ }^{5}$ and they therefore devised a systematic means of rating blindly, from $\mathrm{E}^{2}$ recorded interviews, the relatives' expressed emotion. ${ }^{6}$ Two prospective studies showed that a high rating for hostility, $\vec{\nabla}$ critical comments, or overinvolvement in the relative most in 8 contact with the patient strongly predicted relapse during the $\frac{9}{3}$ nine months after discharge from hospital. ${ }^{7} 8$

Of 128 acute schizophrenics, 57 had relatives with high ratings for expressed emotion (high EE). Twenty nine of the $57(51 \%)$ relapsed in the nine months after discharge com- $\overrightarrow{0}$ pared with $13 \%$ of patients returning to low EE environments. Nearly identical results have been reported in California. ${ }^{9} \mathrm{O}$ Moreover, in the British studies those patients in contact with high EE relatives for more than 35 hours a week had twice the relapse rate of those with little contact. Maintenance $\stackrel{0}{\circ}$

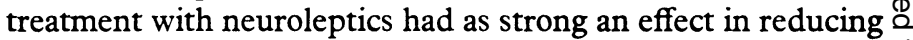
the relapse rate as had the amount of contact between the $\overrightarrow{\overrightarrow{0}}$ patient and his high EE relative, and the two effects were 3 independent. Almost all patients in high contact with high $\mathrm{EE}$ relatives and off medication relapsed, but only $15 \%$ relapsed among patients in low contact and on medication. In the group which had one protective factor but not the other-low contact or maintenance medication-about half relapsed. None $\frac{5}{3}$ of the $14 \%$ of patients living with low EE relatives who relapsed were taking neuroleptics, and in Leff and Vaughan's $\frac{\rho}{3}$ cohort there were no relapses among patients taking medication 0 and living with relatives rated low for expressed emotion. ${ }^{10} \stackrel{\sim}{\sim}$ Thus living with unprovocative relatives or living with o provocative relatives but having a low level of contact with $\frac{D}{0}$ them while taking neuroleptics are good prognostic factors with about a $15 \%$ chance of relapse in the nine months after $\mathrm{N}$ discharge.

The occurrence of arousing life events is another independent variable which may provoke relapse. If such life events provoke an exacerbation of symptoms or a relapse in $\stackrel{\mathscr{\Phi}}{?}$ schizophrenia they would be expected to be more common 0 in patients just before an acute episode than in a control population. Brown and Birley found just this in a study of $\stackrel{\mathbb{P}}{\mathcal{P}}$ 50 consecutive admissions to the Maudsley Hospital. ${ }^{11}$ Life $\stackrel{\complement}{\varrho}$ events had, however, recently occurred more commonly? among patients on medication when they relapsed. A similar 8 observation emerged from two studies of chronic patients. These found that almost all those who relapsed on medication 
had had a life event in the preceding five weeks, but life events were not more common in patients who relapsed off medication. ${ }^{12}$ Leff and colleagues found that patients who relapse on medication are more likely both to have life events and high EE relatives, ${ }^{13}$ but most patients $(81 \%)$ who relapsed off medication had just one or the other of these factors. ${ }^{14}$

These results indicate that schizophrenics are sensitive to environmental conditions which are emotionally arousing, such as contact with high EE relatives, but that the influence of these may be moderated both by avoiding such contact and by taking neuroleptics. Life events can act as additional risk factors and may also provoke relapse in patients protected by medication. Taken with exposure to high EE relatives they explain most relapses which occur during maintenance treatment with neuroleptics.

Until recently the direction of causality in this model has been in question because patients with a more severe illness who are more likely to relapse are just the patients whom one would expect to be at home, unable to go out, and in greater contact with their relatives, from whom they might elicit hostility and overinvolvement. They are also the group least likely to take their medication.

Leff and colleagues ${ }^{13}$ hypothesised that if a high level of contact with high EE families is the cause of relapse, then the $50^{\circ}$, relapse rate over nine months observed in patients discharged taking medication who live with high $\mathrm{EE}$ relatives should fall below $15 \%$ if either patients reduced their contact with the relatives or the relatives reduced their expressed emotion. In a randomised trial 24 patients from high EE homes were given maintenance phenothiazines, mostly the long acting depot injection fluphenazine decanoate, and either followed up as controls in normal outpatient attendances or put into an experimental intensive family treatment programme. This included two lectures about schizophrenia, a relatives' group to help those with high expressed emotion cope better with everyday problems posed by the patient and reduce their own isolation, and sessions with the patient and parent to reduce expressed emotion and encourage the relatives to have less contact with the patient.

The results showed a significant fall in critical comments or contact between patient and relative in eight of the 11 experimental families but no fall in the control families. The relapse rate was as predicted: over nine months half of the control group and $9 \%$ of the experimental group relapsed $(p=0.04)$. This result not only substantiates the causal effects of relatives' expressed emotion on the relapse of schizophrenia but also shows the effectiveness of a form of social management. Two previous studies provide reasonably controlled data which are consistent with these findings but less impressive, partly because of the structure of the study and partly because of the relatively weak nature of the intervention. ${ }^{15-17}$ Falloon and colleagues, ${ }^{18}$ using a different therapeutic model, also compared family therapy at home with clinic based individual supportive care in 36 patients taking neuroleptic medication who were considered to be at high risk of relapse because of strong expressed emotion among relatives or for other reasons. At the end of nine months only one family treated patient $(6 \%)$ had relapsed compared with eight patients $(44 \%)$ in the individually treated group, a result wholly consistent with the British findings.

A consistent picture emerges from these controlled studies. Schizophrenics respond to social understimulation by regressing and withdrawing. When stressed by environmental events, rapid social changes, or pressure from overcritical or overprotective relatives they become acutely disturbed. Modulation of both aspects of their environment improves their level of function and greatly reduces their risk of relapse, especially when combined with maintenance neuroleptics, which have an independent and equally potent effect in reducing the risk of relapse. The newest finding is that a programme of family treatment can even further reduce the relapse rate for certain patients previously at risk despite their taking maintenance medication.

S R HIRSCH

Professor of Psychiatry,

Charing Cross Hospital Medical School

London W6 8RF

${ }^{1}$ Bleuler M. The long-term course of the schizophrenic psychoses. Psychol Med $1974 ; 4: 244-54$.

2 Goffman E. Asylums: essays on the social situation of mental patients and other inmates. New York: Doubleday, 1961

${ }^{3}$ Wing JK, Brown GW. Institutionalism and schizophrenia. Cambridge: Cambridge University Press, 1970.

${ }^{1}$ Wing JK, Bennet DH, Denham J. The industrial rehabilitation of long-stay schizophrenic patients. London: HMSO, 1964. (Medical Research Council Memo No 42.)

s Brown GW, Bone M, Dalison B, Wing JK. Schizophrenic and social care: a comparative follow-up of 339 schizophrenic patients. London: Oxford University Press, 1966. (Maudsley Monograph No 17.)

${ }^{6}$ Brown GW, Rutter M. The measurement of family activities and relationships. A methodological study. Human Relations 1966;19: 241-63.

${ }^{7}$ Brown GW, Birley JLT, Wing JK. Influence of family life on the course of schizophrenic disorders: a replication. Br f Psychiatry 1972;121: 241-58.

${ }^{8}$ Vaughan C, Leff JP. The influence of family and social factors on the course of psychiatric illness: a comparison of schizophrenic and depressed neurotic patients. Br F Psychiatry 1976;129:125-37.

${ }^{9}$ Snyder K, Liberman R. Family assessment and intervention with schizophrenics at risk for relapse. In: Goldstein M, ed. New directions for mental health services: new developments in intervention with families of schizophrenics. No 12. San Francisco: Jossey-Bass, 1981.

${ }^{10}$ Leff JP, Vaughan C. The role of maintenance therapy and relatives' expressed emotion in relapse of schizophrenia: a two-year follow-up. Br F Psychiatry 1981;139:102-4.

11 Brown GW, Birley JLT. Crises and life changes and the onset of schizophrenia. F Health Soc Behav 1968;9:203-14.

12 Leff JP, Hirsch SR, Gaind R, Rhodes PD, Stevens BC. Life events and maintenance therapy in schizophrenic relapse. Br F Psychiatry 1973; 123:659-60.

${ }^{13}$ Leff J, Kuipers L, Berkowitz R, Eberlein-Vries R, Sturgeon D. A controlled trial of social intervention in the families of schizophrenic patients. Br F Psychiatry $1982 ; \mathbf{1 4 1}: 121-34$

14 Leff JP, Vaughan C. The interaction of life events and relatives' expressed emotion in schizophrenia and depressive neurosis. $B r f$ Psychiatry $1980 ; 136: 146-53$.

${ }^{15}$ Goldstein MJ, Rodnick EH, Evans JR, May PRA, Steinberg MR. Drug and family therapy in the aftercare of acute schizophrenics. Arch Gen Psychiatry 1978;35:1169-77.

${ }^{16}$ Hogarty GE, Goldberg SC, Schooler NR, Ulrich RF. Drug and sociotherapy in the aftercare of schizophrenic patients: II. Two-year relapse rates. Arch Gen Psychiatry 1974;31:603-8.

i Hogarty GE, Schooler NR, Ulrich R, Mussare F, Ferro P. Fluphenazine and social therapy in the aftercare of schizophrenic patients. Relapse analyses of a two-year controlled study of fluphenazine decanoate and fluphenazine hydrochloride. Arch Gen Psychiatry 1979;36:1283-94.

${ }_{18}$ Falloon IRH, Boyd JL, McGill CW, Razani J, Moss HB, Gilderman AM. Family management in the prevention of exacerbation of schizophrenia : a controlled study. $N$ Engl F Med 1982;306:1437-40. 